\title{
Fatigue Performance and Multiscale Mechanisms of Concrete Toughened by Polymers and Waste Rubber
}

\author{
Bo Chen, ${ }^{1,2}$ Liping Guo, ${ }^{1,3}$ and Wei Sun ${ }^{1,3}$ \\ ${ }^{1}$ School of Materials Science and Engineering, Southeast University, Dongnan Daxue Road No. 2, Nanjing 211189, China \\ ${ }^{2}$ State Key Laboratory of Hydrology-Water Resources and Hydraulic Engineering, Nanjing Hydraulic Research Institute, \\ Nanjing 210029, China \\ ${ }^{3}$ Jiangsu Key Laboratory of Construction Materials, Nanjing 211189, China
}

Correspondence should be addressed to Liping Guo; guoliping691@163.com

Received 22 April 2013; Revised 8 December 2013; Accepted 15 December 2013; Published 2 January 2014

Academic Editor: Jun Zhang

Copyright (C) 2014 Bo Chen et al. This is an open access article distributed under the Creative Commons Attribution License, which permits unrestricted use, distribution, and reproduction in any medium, provided the original work is properly cited.

For improving bending toughness and fatigue performance of brittle cement-based composites, two types of water-soluble polymers (such as dispersible latex powder and polyvinyl alcohol powder) and waste tire-rubber powders are added to concrete as admixtures. Multiscale toughening mechanisms of these additions in concretes were comprehensively investigated. Four-point bending fatigue performance of four series concretes is conducted under a stress level of 0.70 . The results show that the effects of dispersible latex powder on bending toughness and fatigue life of concrete are better than those of polyvinyl alcohol powder. Furthermore, the bending fatigue lives of concrete simultaneously containing polymers and waste rubber powders are larger than those of concrete with only one type of admixtures. The multiscale physics-chemical mechanisms show that high bonding effect and high elastic modulus of polymer films as well as good elastic property and crack-resistance of waste tire-rubber powders are beneficial for improving bending toughness and fatigue life of cementitious composites.

\section{Introduction}

With the rapid development of high-rise building and longspan concrete bridges in China, demands of high strengths and high toughness of concrete materials are more and more highlighted in the latest decade. Because of the obvious brittleness, high strength concrete structures are always suddenly fractured without any warning under fatigue and earthquake actions. Besides, cracks introduced by these dynamic loads are entrance of corrosion ions such as chloride, dioxide, and sulfate, which would make durability of concrete structure degraded. Therefore, upgrading toughness is a necessary way to improve the durability of cement-based composites. It has been noted that material toughness depends on material components, microstructure morphology and mechanics, and so forth. Because of shrinkage, random microcracking could not be prevented inside of concrete. That means the optimized cost-effective methodologies for toughness improvement of concrete is a big challenge so far. Many scientists (Dry [1], Ye [2], Guneyisi et al. [3], etc.) have done many researches to decrease porosity, homogenize microstructure, enhance bond strength between aggregate and hardened cement paste, and decelerate crack growth through fiber reinforcement, polymer toughening, and nanoparticles. However, fibers and nanomaterials are too expensive to be applied in practice in wide range. Instead, polymers and reactive industry waste particles or powder could be better choice even though a slight decrease of concrete strength occurs.

The present research employed two types of watersoluble polymers (such as dispersible latex powder and polyvinyl alcohol powder) and waste tire-rubber powders as constituents for toughness improvement. Primary strengths, bending toughness, and fatigue performance of concrete with polymers or/and waste tire-rubber powders were evaluated. The optimized concrete mixture is recommended 


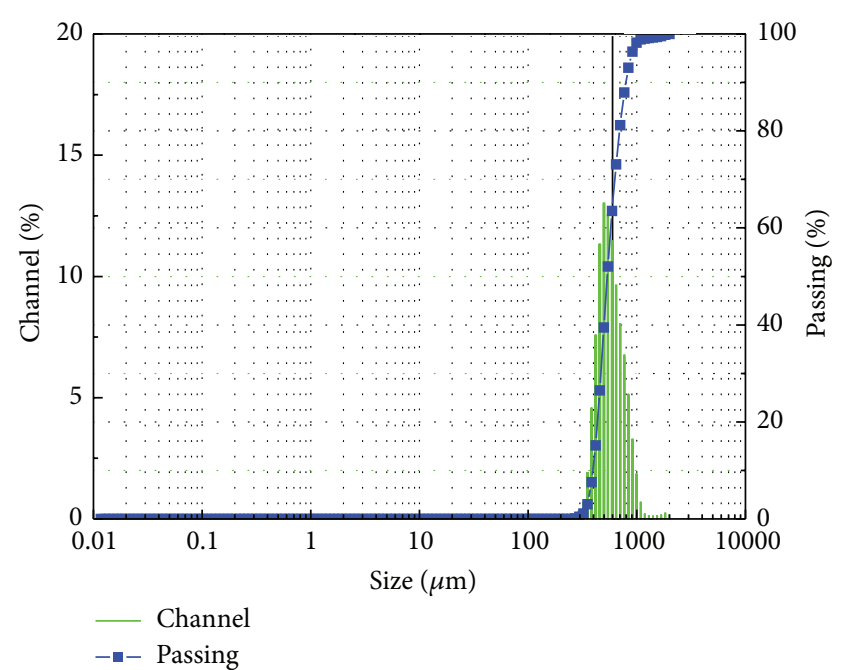

FIgURe 1: Particle size distribution of waste tire-rubber powder.

after investigation. Furthermore, the related nano-micromacro-multiscale mechanisms of these concretes were also comprehensively investigated.

\section{Raw Materials and Specimen Preparation}

P.II 42.5 Portland cement (C) and silica fume (SF) were used as binder materials in concrete. The specific surface area of cement and silica fume is $400 \mathrm{~m}^{2} / \mathrm{kg}$ and $26000 \mathrm{~m}^{2} / \mathrm{kg}$, respectively. Continuous gradations of Basalt gravel $(\mathrm{G})$ and river sand $(S)$ were employed as coarse and fine aggregate. The fineness modulus of fine aggregate was 2.7. The size range of coarse aggregate was $5-10 \mathrm{~mm}$. The bulk density of coarse and fine aggregate was $1500 \mathrm{~kg} / \mathrm{m}^{3}$ and $1890 \mathrm{~kg} / \mathrm{m}^{3}$, respectively.

Two types of water-soluble polymers were selected as one of the toughening additions, that is, dispersible latex powder (LP) and polyvinyl alcohol powder (PVA). The main physical-chemistry properties of LP are listed as follows: $400 \sim 500 \mathrm{~g} / \mathrm{L}$ of relative density $\left(25^{\circ} \mathrm{C} / 4^{\circ} \mathrm{C}\right), 0.3 \sim 80$ microns of particle size distribution, 8 of $\mathrm{pH}$ value, $-10^{\circ} \mathrm{C}$ of glass transition temperature, and $0^{\circ} \mathrm{C}$ of film-forming temperature. The $1300 \mathrm{~g} / \mathrm{L}$ of relative density $\left(25^{\circ} \mathrm{C} / 4^{\circ} \mathrm{C}\right), 75 \sim 85^{\circ} \mathrm{C}$ of glass transition temperature, and $0^{\circ} \mathrm{C}$ of film-forming temperature for PVA 24-88. The waste tire-rubber powder (RP) was employed as the second toughening phase for the concrete. The physical properties and particle size distribution of it were listed in Table 1 and Figure 1, separately. The bulk density of it is $380 \mathrm{~kg} / \mathrm{m}^{3}$.

In addition, the polycarboxylate superplasticizer with 20\% 30\% water-reducing ratio and 40\% solid content was applied for adjusting the slump of fresh concrete to be $180 \mathrm{~mm}$ $\pm 20 \mathrm{~mm}$. All these powders and solutions were mixed by the tap water (W) within a compulsory concrete mixer in room temperature. The designed strength grade of concrete was C40. The water-to-binder ratio (mass ratio of mixing water to total mass of cement and silica fume) is 0.45 in mass. To prevent decomposition of the polymer film through reducing the content of calcium hydroxide in concrete microstructure
TABLE 1: Physical properties of waste tire-rubber powder.

\begin{tabular}{lccc}
\hline Color State & $\begin{array}{c}\text { Mean size } \\
(\mu \mathrm{m})\end{array}$ & $\begin{array}{c}\text { Tensile strength } \\
(\mathrm{MPa})\end{array}$ & $\begin{array}{c}\text { Ultimate } \\
\text { elongation }(\%)\end{array}$ \\
\hline Black Powder & 425 & 11 & 440 \\
\hline
\end{tabular}

TABLE 2: Mix design of concrete $\left(\mathrm{kg} / \mathrm{m}^{3}\right)$.

\begin{tabular}{lcccccccc}
\hline Series & C & SF & S & G & W & LP & PVA & RP \\
\hline Ref & 450 & 50 & 617.5 & 1007.5 & 225 & 0 & 0 & 0 \\
H1 & 450 & 50 & 617.5 & 1007.5 & 225 & 15 & 0 & 0 \\
H2 & 450 & 50 & 617.5 & 1007.5 & 225 & 0 & 15 & 0 \\
H3 & 450 & 50 & 588.5 & 1007.5 & 225 & 15 & 0 & 29 \\
H4 & 450 & 50 & 588.5 & 1007.5 & 225 & 0 & 15 & 29 \\
\hline
\end{tabular}

and simultaneously to improve the strengths of hardened concrete, $10 \%$ by mass of the cement was replaced with silica fume. The mix design of tested concrete in the present research was shown in Table 2, wherein $23.4 \%$ by volume of fine aggregate was replaced with the waste tire-rubber powder in H4. Ref is the controlled plain mixture.

The specimen size was $150 \mathrm{~mm} \times 150 \mathrm{~mm} \times 150 \mathrm{~mm}$ for compressive test and $100 \mathrm{~mm} \times 100 \mathrm{~mm} \times 400 \mathrm{~mm}$ for bending test. The preparation process for casting specimens should be paid special attention. The aggregates and waste rubber powder were mixed in dry condition for $1 \mathrm{~min}$ at first, and then cement and silica fume were put into the mixer for additional $2 \mathrm{~min}$. Finally, the polymers were dissolved in mixing water before slowly putting then into the dry mixtures, keeping on mixture for additional $2 \mathrm{~min}$ and selfleveling in the steel moulds within $24 \mathrm{~h}$. After demould, the specimens were moved into the standard curing room $\left(20 \pm 2^{\circ} \mathrm{C}, \mathrm{RH}>95 \%\right)$ for 14 days and then cured in room conditions $\left(20 \pm 2^{\circ} \mathrm{C}\right.$, RH $\left.65 \pm 5 \%\right)$ until test. The specimens with hydration age of 56 days were ready for the following experiments.

\section{Experimental Results of Strengths and Bending Toughness}

3.1. Compressive and Bending Strengths. The compressive and flexural strengths were conducted for primary evaluations according to the Chinese Standard GB/T 500812002 "Standard for test method of mechanical properties on ordinary concrete." An electronic mechanical testing machine was employed for this purpose. The loading velocity was $0.5 \mathrm{MPa} / \mathrm{s}$ and $0.05 \mathrm{MPa} / \mathrm{s}$ for compressive and 4 -point bending strength test, respectively. The average value of 6 test data was adopted as the final results for each concrete series, as presented in Figure 2. Except for the compressive strength of $\mathrm{H} 4$ which is lower than the designed strength grade C40, those of others are satisfied with the designed one.

Figure 2 shows that strengths of $\mathrm{H} 1$ are top among those of other concrete series, and strengths of Ref series are similar to those of $\mathrm{H} 2$. The compressive strength of $\mathrm{H} 1$ with LP is 1.3 times of Ref concrete and 1.4 times of $\mathrm{H} 2$ with PVA, while the bending strengths of them are similar to each other. However, 


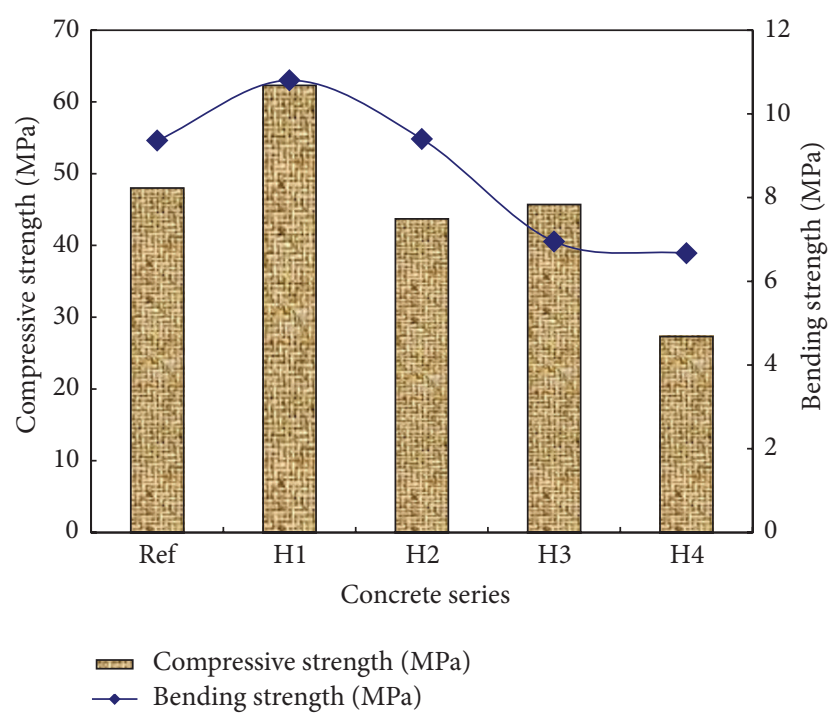

FIGURE 2: Test results of concrete strengths at hydration age of 56 days.

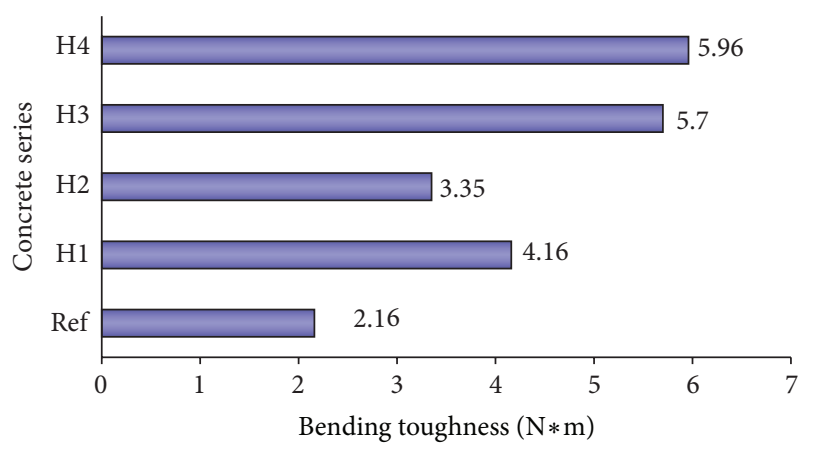

FIGURE 3: Bending toughness of four series concretes.

addition of waste tire-rubber powders does not dramatically weaken the compressive strength of $\mathrm{H} 3$, but it obviously decreases the bending strengths of $\mathrm{H} 3$ and $\mathrm{H} 4$. The strengths of $\mathrm{H} 3$ are about $65 \%$ of those of $\mathrm{H} 1$. The same law also happens between $\mathrm{H} 2$ and $\mathrm{H} 4$. Because of low elastic modulus and compressibility [4], the waste tire-rubber particles endure the compressive and tensile stress as well as could not restrain the concrete displacement under loading [4].

Besides, the test results by Nehdi and Khan [5], Toutanji [6], Topcu [7], and Fattuhi and Clark [8] show that addition of waste tire-rubber powder obviously increases the voids content of concrete, which is another resource for low strengths of concrete. That is the reason to employ silica fume in the present study for remedying this weakness of waste tirerubber powder.

3.2. Evaluations on Bending Toughness. In order to evaluate the toughness of concrete through polymers and waste rubber powder, the integral area enclosed by 4-point bending load and max middle displacement curves was defined as the bending toughness of concrete without precut notch according to the Chinese Standard GB/T 50081-2002.
TABLE 3: Fatigue lives of four tested concrete series.

\begin{tabular}{lccccc}
\hline Series & Ref & H1 & H2 & H3 & H4 \\
\hline $\begin{array}{l}\text { Fatigue life } \\
\text { (cycles) }\end{array}$ & 323,891 & 775,731 & 202,552 & $2,190,810$ & $2,235,207$ \\
\hline
\end{tabular}

The specimens with size of $100 \mathrm{~mm} \times 100 \mathrm{~mm} \times 400 \mathrm{~mm}$ were conducted the bending load with a velocity of $0.05 \mathrm{~mm} / \mathrm{min}$. The bending toughness of tested four series concretes were displayed in Figure 3.

It is known that coupled actions of polymers and rubber powders on bending toughness of concrete are positive dramatically. The bending toughness of Ref is lower than other series. The bending toughness of $\mathrm{H} 3$ and $\mathrm{H} 4$ is $50 \%$ higher than those of $\mathrm{H} 1$ and $\mathrm{H} 2$. Because of elastic properties and good physical-chemistry cohesion of polymer film and rubber particles, new starts and extensions of microcracks are difficult inside of concrete [5-8]. The cracking energy absorption in plastic zone of crack tips is enhanced to delay the progress of cracks.

\section{Fatigue Performance}

Generally, the fatigue stress is only adopted less than $50 \%$ of ultimate strength (i.e., fatigue stress level is less than 0.50) for the concrete structure design in practice. For the normal plain concrete, the fatigue life could be more than 2 million cycles at fatigue stress level of 0.55 [9]. In order to contrast the difference of fatigue lives between polymer concrete and polymer-rubber toughened concrete in lab, a stress level 0.70 was applied for fatigue test. Whose fatigue life is longer, its toughness is higher.

4.1. Testing Setup and Parameters. A fatigue test was conducted by MTS flexure fatigue testing machine equipped with closed-loop system and MTS fatigue controller. Its max dynamic load is $\pm 250 \mathrm{kN}$. The prisms with hydration age of 56 days were subjected to unidirectional cyclic loading by a 4 -point bending setup. Each of them was loaded by applying two cyclic forces on the cross-sections at $1 / 3$ and $2 / 3$ of the net span. The cyclic bending stress was carried out by a hydraulic press with constant amplitude of sinusoidal load. The frequency of fatigue load was $10 \mathrm{~Hz}$. A constant load ratio of 0.1 between min and max fatigue stresses was selected for the present study. Moreover, two million cycles were assumed as concrete fatigue limit for evaluations on fatigue performance of tested concrete.

4.2. Results and Analysis. The fatigue lives of tested four concrete series were drawn in Table 3. It is evident that only tested fatigue cycles of polymer-rubber toughened concrete (H3 and H4) are larger than two million cycles but still nonfracture happens. On the contrary, the fatigue lives of polymer concrete are less than this assumed fatigue limit. Moreover, those of Ref are shortest among those of other series. That means using water-soluble polymers alone could not dramatically improve the fatigue life of concrete. 


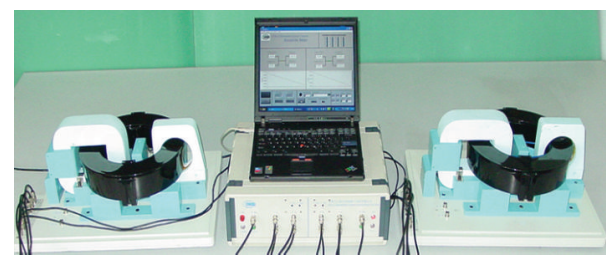

FIGURE 4: A novel noncontact electrical resistivity instrument.

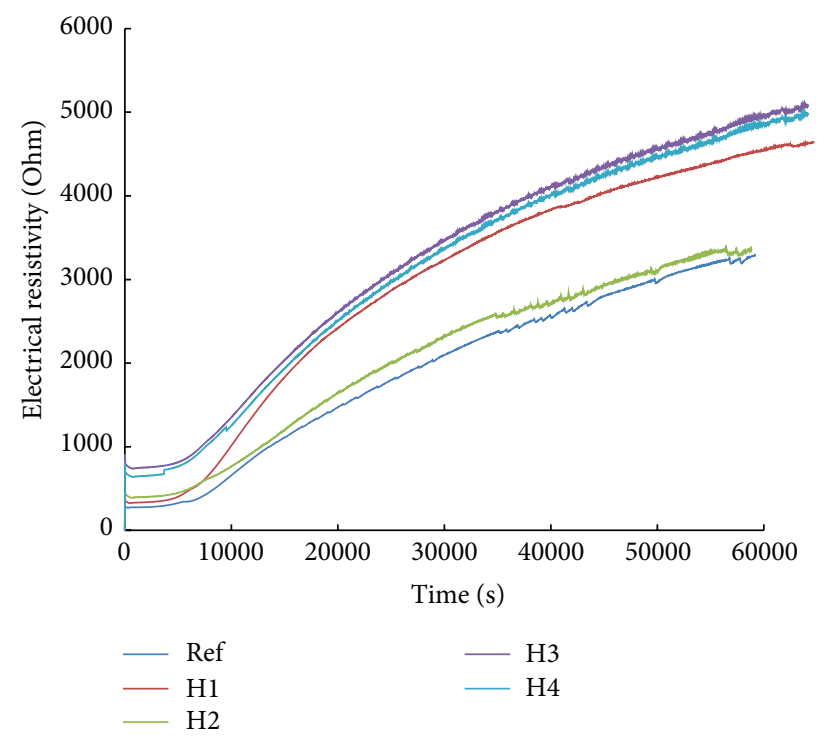

FIgURE 5: The resistivity-time curves of tested concrete series.

They should be coupled with the elastic particles like waste tire-rubber to achieve the outstanding fatigue performance for cement-based composites. Besides, microfilling effect and pozzolanic reactions of nanoscale silica fume contribute to the fatigue performance of concrete as well. Moreover, the laws deduced from Table 3 are closely related to Figure 3. With higher bending toughness, bending fatigue lives will be longer.

\section{Multiscale Mechanisms Analysis}

As mentioned in Sections 3 and 4, the primary mechanical behaviors and fatigue performance of tested concretes are closely determined by the physical-chemistry properties of particle additions and the optimized mix design of concrete. Therefore, the multiscale mechanisms of the toughened concrete were comprehensively investigated in this section.

5.1. Macroscale Detections. For detecting the electrical resistivity and hydration rate of cement-based materials with different additions at early age, the cement-based pastes of tested concretes were ready for this test according to the mix design listed in Table 2. Except nonincluded gravels and sands, the mass fractions of other raw materials are constant for casting cement-based pastes.
A novel noncontact electrical resistivity instrument (shown in Figure 4) was utilized. The electrical current comes from migrations of some charged alkali ions in cement paste. The resistivity-time curves of tested concrete series were shown in Figure 6. Wherein, the first inflection point on each curve was defined as the characteristic point $I$ of the electrical resistivity. From this time point, the network microstructure composed of cement and hydrates was initially formed.

Figure 5 reveals that resistivity would increase with cement hydration time. The test results of specimens with rubber particles and polymers are larger than those of others with only polymers. Those of $\mathrm{H} 1, \mathrm{H} 3$, and $\mathrm{H} 4$ are dramatically higher than that of the reference series.

Besides, the time point and absolute value of characteristic points $I$ are influenced by polymers and rubber particles, wherein the time point of $I$ for $\mathrm{H} 1$ is $5000 \mathrm{~s}$ which is slightly earlier than those of others, 7000 s. It means that LP could accelerate the cement hydration in early time. Furthermore, the resistivity of paste with PVA increases slower than the data of the one with LP. However, the tested resistivities of $\mathrm{H} 3$ and $\mathrm{H} 4$ are greater than those of other series, and are similar to each other.

5.2. Microscale Analysis. As testing results of bending toughness and fatigue performance in Section 4, the microstructure morphology and components evolution are the critical factors for those macroscopic behaviors of cementbased concrete. In this section, a field emission electron microscope (ESEM) coupled with an energy dispersive Xray spectroscopy (EDS) was employed for the following investigations. The ESEM images of concrete microstructures with LP and PVA at different ages were presented in Figures 6 and 7, respectively. Corresponding components analysis of concrete microstructure with LP and PVA were detected and quantitatively calculated by the EDS and independently shown in Figures 8 and 9.

After comparing Figures 6(a) and 7(a), we can find that the concrete microstructure of concrete with LP is porous in the first age of 3 days. Most of cement particles are not hydrated at this age, because the atomic percentage of calcium and silica ions is still less than 1.0 (Figure 8(a)) like those of unhydrated Portland cement. At the hydration age of 28 days, the LP polymer films could be found to attach on cement hydrates; in addition, a relative uniform network microstructure could be detected in Figure 6(b).

As far as the concrete microstructure with PVA polymer is concerned, the same phenomena were detected as well. At the hydration age of 3 days, the PVA film could not be formed uniformly in cement paste matrix but scattered inside of big voids like ESEM images in Figure 7(a). Accordingly, the atomic percentage of calcium-silica ions is not larger than 1.0 as well, as shown in Figure 9(a). With the increase of hydration age to be 28 days, the PVA films are uniformly covered on cement hydrates and exist in cement-aggregate interfacial zone, as shown in Figure 7(b).

It is also revealed from EDS analysis results shown in Figures 8 and 9 that the atomic percentage of calcium and silica ions is 2.3 for concrete with LP and 2.5 for the ones with 


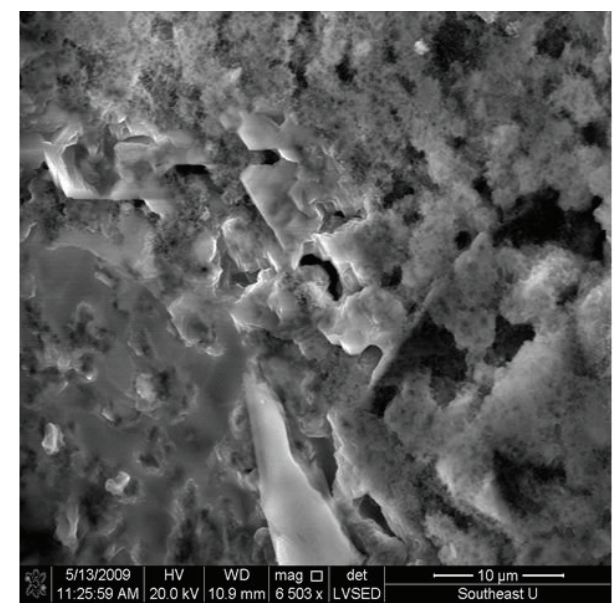

(a)

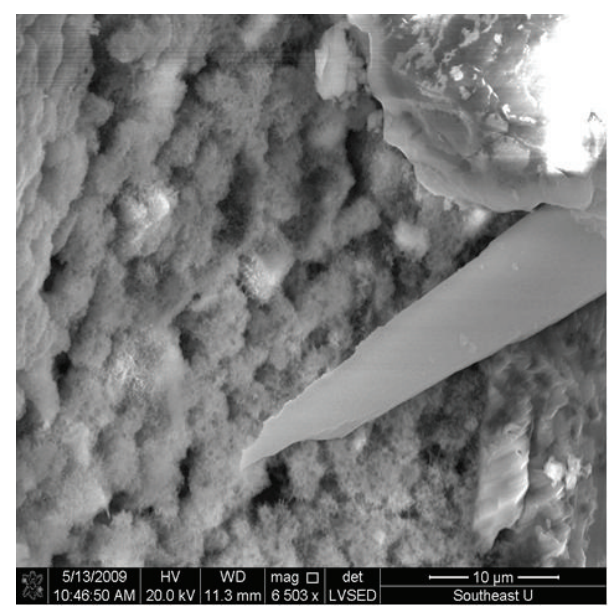

(b)

FIGURE 6: ESEM images of concrete microstructure with LP at different hydration ages: (a) 3 days and (b) 28 days.

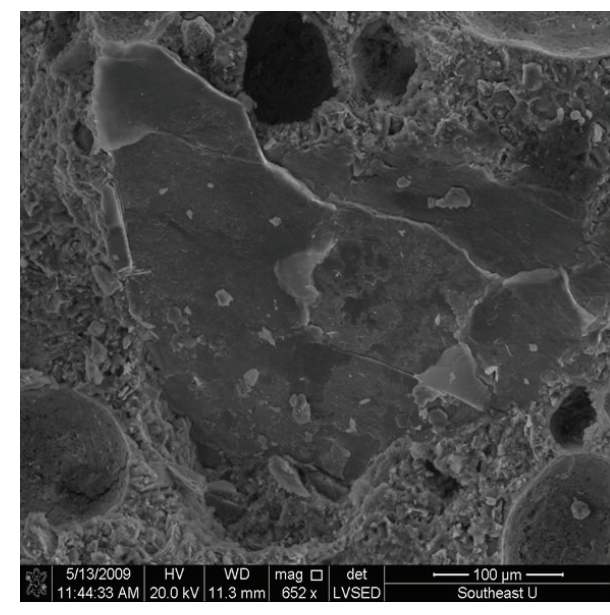

(a)

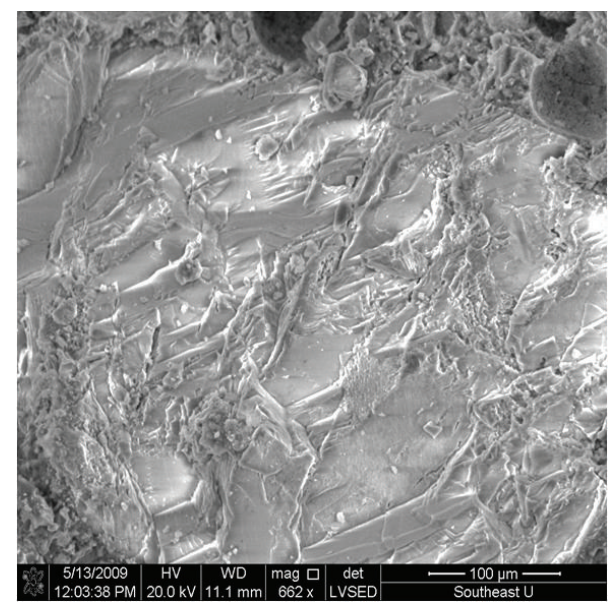

(b)

FIGURE 7: Microstructure morphologies of concrete with PVA at different hydration ages: (a) 3 days and (b) 28 days.

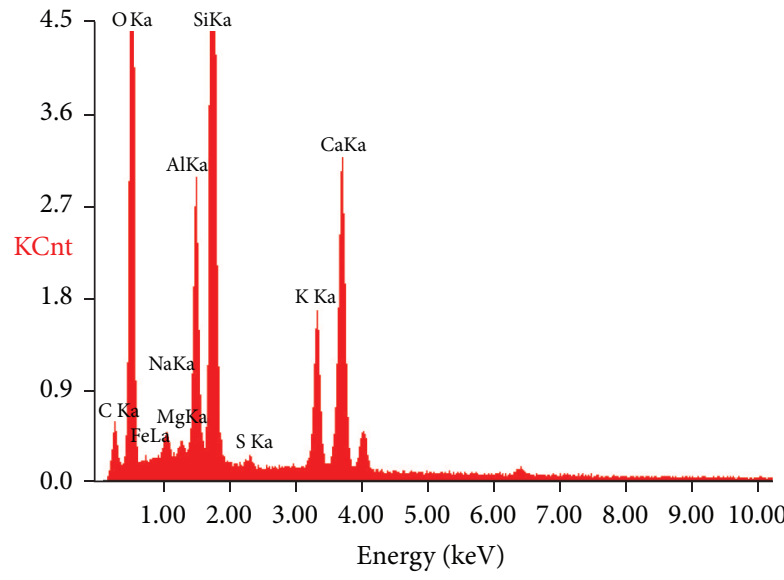

(a)

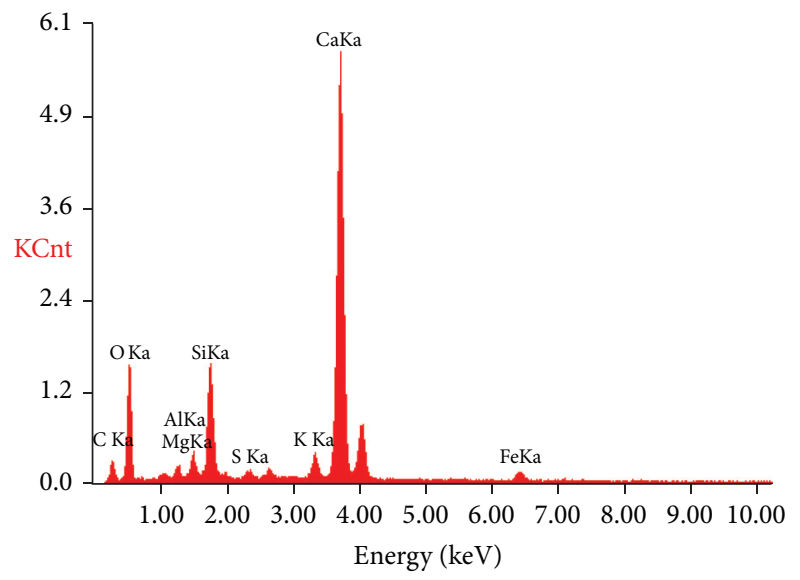

(b)

FIGURE 8: EDS analysis on concrete with LP at different hydration ages: 3 days (a) and 28 days (b). 


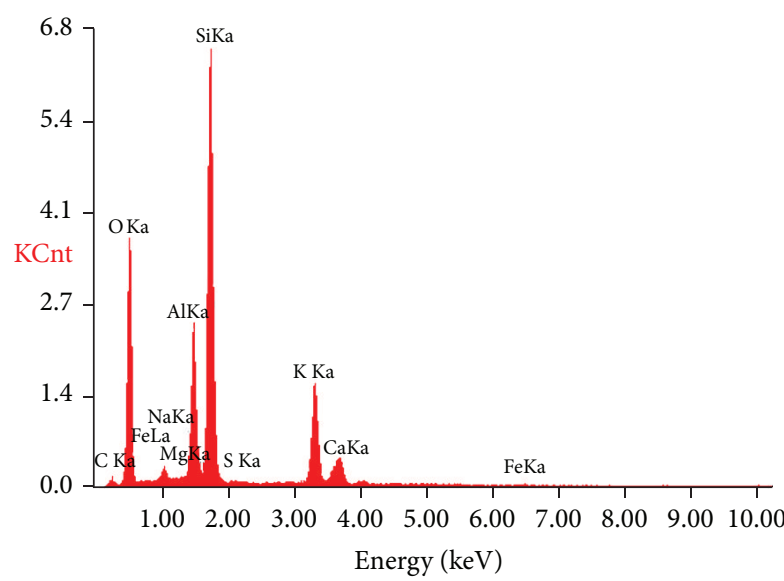

(a)

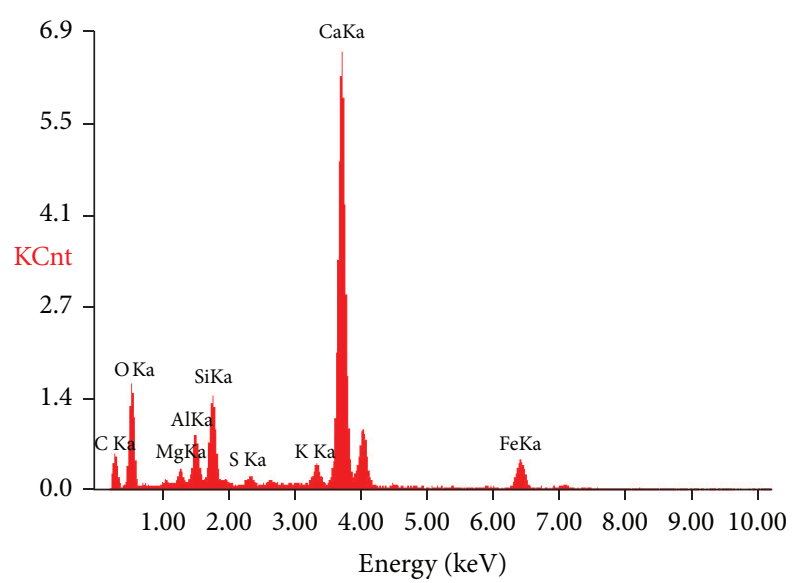

(b)

FIGURE 9: EDS analysis on concrete with PVA at different hydration ages: 3 days (a) and 28 days (b).

PVA, respectively. They are exactly the evidences to enhance the bonding strength of calcium silicate hydrate gel (Type II C-S-H gels with network structure) in microstructure of concrete at 28-day hydration age.

Therefore, these network microstructures covered by polymer film and the hydrated dense C-S-H gels are proposed to be one of the microscale mechanisms for improved bending toughness and fatigue performance of cement-based concrete.

5.3. Nanoscale Evaluations. As we know the polymer films in cement paste matrix and in cement-aggregate interfacial zone have positive effects on the strengths, bending toughness, and fatigue performance of cement-based composites. The inherent material properties of these films were separately evaluated through a novel nanoindentation system. The LP and PVA films were artificial conducted on the surface of a steel slice. Firstly, these polymer powders were dissolved in the deionized water. Secondly, put a droplet of polymer suspension on a steel slice for polymer film formation. And then let them naturally dry in room conditions $\left(20 \pm 2^{\circ} \mathrm{C}\right.$, $\mathrm{RH} 60 \pm 5 \%$ ) for one week. The hardened polymer films were ready for the following nanoindentation tests. We adopted two different testing modes for the tested polymer films. A nanodynamic mechanical analysis (nano-DMA) mode and a static mode were employed for tests on LP film and PVA film, respectively. The $250 \mathrm{~Hz}$ loading frequency, conducted dynamic load of $5 \mu \mathrm{N}$, and static load of $100 \mu \mathrm{N}$ were employed for the nano-DMA mode. Moreover, a max load of $500 \mu \mathrm{N}$ and loading and unloading velocities of $100 \mu \mathrm{N} / \mathrm{s}$ were selected for the static mode.

The tested result of elastic modulus was $3.39 \mathrm{GPa}$ for the LP film and $3.93 \mathrm{GPa}$ for the PVA film. They are two orders of magnitudes higher than those of tire-rubber particles. Wherefore, except the contributions of dense cement hydrates, the outstanding nanomechanical properties of LP and PVA films are other fundamental mechanisms for high bending toughness and fatigue performance of cement-based concrete.

\section{Conclusions}

Based on the studies of key mechanical behaviors and fatigue performance as well as multiscale mechanisms of concrete with water-soluble polymers (e.g., LP, PVA) or/and waste tirerubber powders, some points could be concluded as follows.

(1) The bending toughness and fatigue life of concrete with LP are larger than those of concrete with PVA. Moreover, the bending fatigue lives of concrete with mixed polymers and waste tire-rubber powders are longer than those of others.

(2) Based on the comprehensive investigations of the multiscale mechanisms by novel instruments, it is revealed that homogeneous microstructures and high toughness as well as outstanding fatigue performance of concrete are attributed to cohesive effect and high elastic modulus of polymer films, dense cement hydrates, and good elastic property and crackresistance of waste tire-rubber powders.

\section{Conflict of Interests}

The authors declare that there is no conflict of interests regarding the publication of this paper.

\section{Acknowledgments}

This work was supported in part by NSFC under Grant no. 51378113 and the Fundamental Research Funds for the Central Universities with Grant no. 26220120012.

\section{References}

[1] C. M. Dry, "Smart earthquake-resistant materials: using timereleased adhesives for damping, stiffening, and deflection control," in Proceedings of the 3rd International Conference on Intelligent Materials and 3rd European Conference on Smart Structures and Materials, vol. 2779 of Proceeding of SPIE, pp. 958-967, 1996. 
[2] G. Ye, Experimental study and numerical simulation of the development of the microstructure and permeability of cementitious materials [Ph.D. thesis], Delft University of Technology, Delft, The Netherlands, 2003.

[3] E. Guneyisi, M. Gesolu, and T. Özturan, "Properties of rubberized concretes containing silica fume," Cement and Concrete Research, no. 34, pp. 2309-2317, 2004.

[4] G. Cheng, G. Q. Zhao, Y. J. Guan, and Q. H. Yuan, "Experimental study on mechanical properities of tyre rubber materials," China Elastomerics, vol. 13, no. 4, pp. 6-9, 2003.

[5] M. Nehdi and A. Khan, "Cementitious composites containing recycled tire rubber: an overview of engineering properties and potential applications," Cement, Concrete and Aggregates, vol. 23, no. 1, pp. 3-10, 2001.

[6] H. A. Toutanji, "The use of rubber tire particles in concrete to replace mineral aggregates," Cement and Concrete Composites, vol. 18, no. 2, pp. 135-139, 1996.

[7] L. B. Topcu, “The properties of rubberized concretes," Cement and Concrete Research, vol. 25, no. 2, pp. 304-310, 1995.

[8] N. I. Fattuhi and L. A. Clark, "Cement-based materials containing shredded scrap truck tyre rubber," Construction and Building Materials, vol. 10, no. 4, pp. 229-236, 1996.

[9] L.-P. Guo, W. Sun, K.-R. Zheng, H.-J. Chen, and B. Liu, "Study on the flexural fatigue performance and fractal mechanism of concrete with high proportions of ground granulated blastfurnace slag," Cement and Concrete Research, vol. 37, no. 2, pp. 242-250, 2007. 

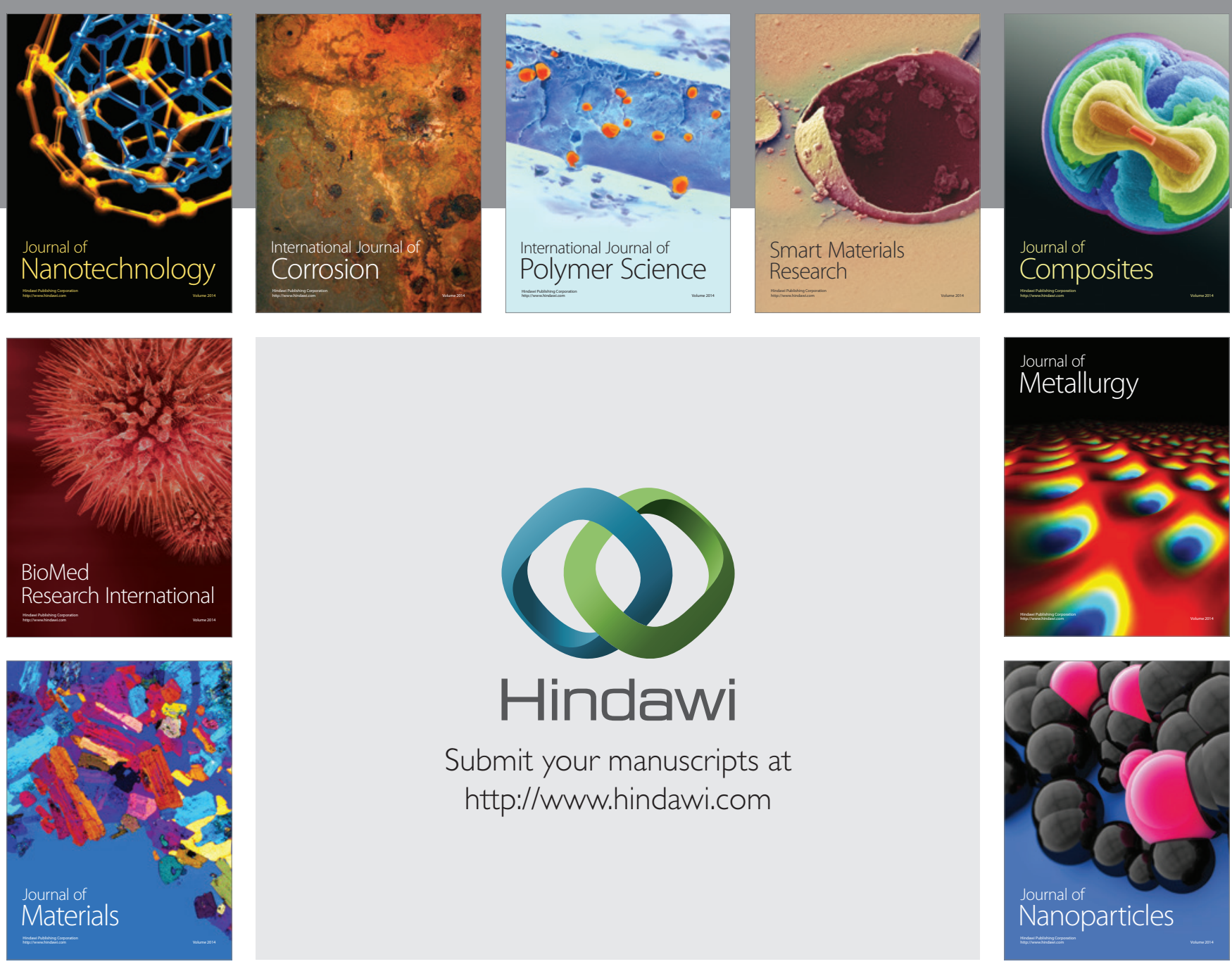

Submit your manuscripts at http://www.hindawi.com
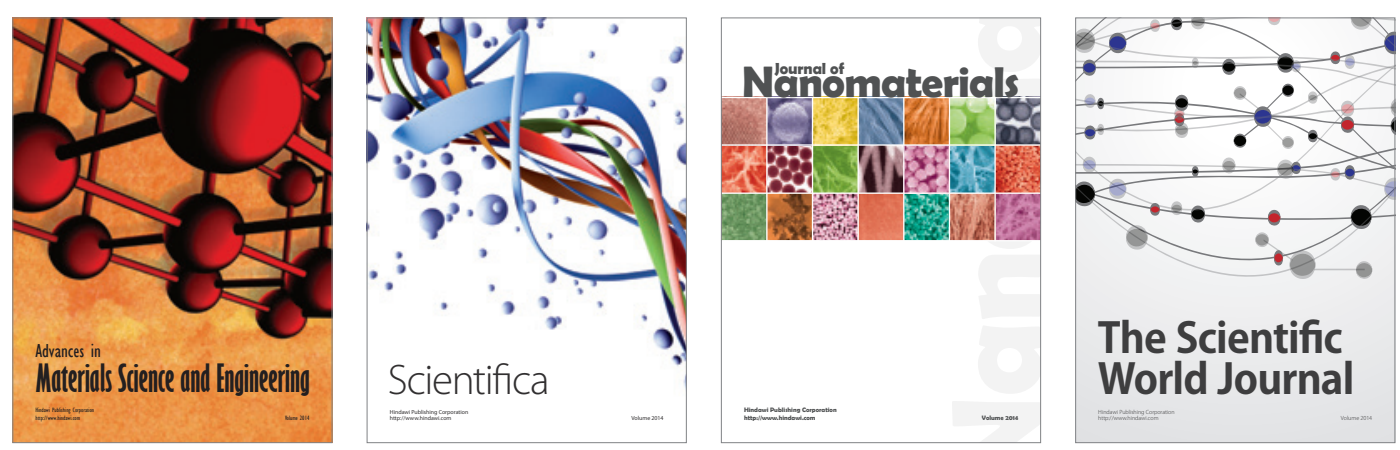

\section{The Scientific World Journal}
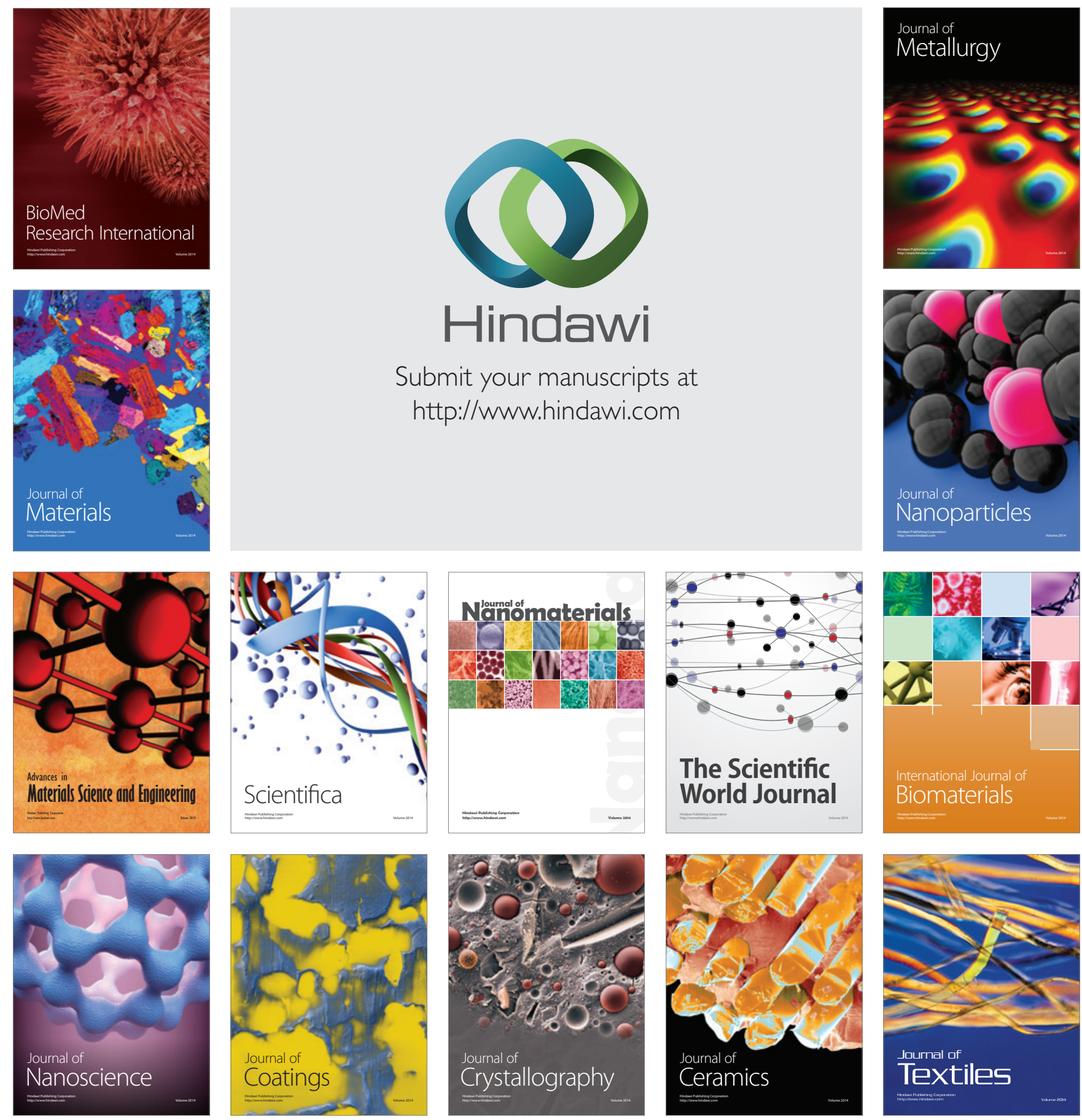